\title{
UN PROYECTO DE JOSÉ RAMÓN DE EGUÍA MADARIAGA Y DE EUGENIO BARRÓN AVIGNÓN PARA EL III DUQUE DE FERNÁN NÚÑEZ
}

\author{
Cristóbal Marín Tovar \\ (Universidad Rey Juan Carlos) \\ cristobal.marin@urjc.es
}

\section{RESUMEN}

En el año 1860, el III duque de Fernán Núñez, encargó al maestro de obras José Ramón de Eguía Madariaga y al ingeniero Eugenio Barrón Avignón, la construcción de un dique para sustituir a uno anterior que fue destruido por una riada del río Jarama.

PALABRAS CLAVE: III duque de Fernán Núñez; José Ramón de Eguía Madariaga; Eugenio Barrón Avignón; Río Jarama; Soto del Malecón.

\section{A PROJECT BY JOSÉ RAMÓN DE EGUÍA MADARIAGA AND EUGENIO BARRÓN AVIGNÓN FOR THE III DUKE OF FERNÁN NÚÑEZ}

\begin{abstract}
In the year 1860, the III duke of Fernán Núñez, commissioned the master builder José Ramón de Madariaga, and the engineer Eugenio Barrón Avignón, the construction of a dike to replace an earlier one that was destroyed by a flood of the Jarama river.
\end{abstract}

KEY WORDS: III duke of Fernán Núñez; José Ramón de Eguía Madariaga; Eugenio Barrón Avignón; Jarama river; Soto of Malecón. 
Don Manuel Falcó D’Addara y Valcálcer, XIV marqués de Almonacid de los Oteros (Milán, 1828 - Aranjuez, 1892), se convirtió en duque consorte de Fernán Núñez, tras contraer matrimonio en Madrid, el 14 de octubre de 1852, con doña María del Pilar Osorio y Gutiérrez de los Ríos (Madrid, 1829 - Namur, Bélgica, 1921), que entre otros títulos poseía los de III duquesa de Fernán Núñez, VIII duquesa de Montellano, V duquesa del Arco y Concha de Cervellón, XIII condesa de Barajas, XII marquesa de Alameda, VIII marquesa de Castel Moncayo, VIII marquesa de Ponds y VI marquesa de Villanueva de las Achas.

Don Manuel Falcó ostentó diversos cargos de importancia, entre los que destacaron el de concejal del Ayuntamiento de Madrid, senador o embajador de España en París. Fue impulsor en 1874 de la creación del Paseo de Carruajes en el parque del Retiro, sufragando de su bolsillo parte del proyecto con 50.000 pesetas de la época.

Como se apunta en La Ilustración Española y Americana del 30 de octubre de $1874^{1}$, esta obra fue objeto de polémica y debate, bien por no considerarse útil o necesaria, o por no ser el paseo lo bastante ancho como para que por él circulasen con comodidad los carruajes, así como por no haber incluido una calle para hacer más cómodo el recorrido de los peatones.

Los comentarios positivos se centraron en que esta nueva vía era "bella, cómoda y ofrece agradables perspectivas", y que animaría a los madrileños a visitar este enorme parque.

La inauguración del paseo tuvo lugar el 22 de octubre de 1874, con asistencia de numerosas personalidades de la aristocracia, y una nutrida representación del pueblo llano. Para la ejecución de este proyecto contó don Manuel con el trabajo de Eugenio de Garagarza y Dugiols, director de Paseos y Arbolados de Madrid, y con el del ingeniero de Caminos, Canales y Puertos, Eugenio Barrón y Avignón, al que había encargado en 1860 la construcción de un nuevo dique en el río Jarama, como veremos más adelante.

Barrón era ya un ingeniero consagrado, y precisamente en ese mismo año de 1874 se inauguraba su viaducto de hierro de la calle Segovia.

Dada la decisiva intervención del duque en esta nueva arteria dentro del parque del Retiro, se la conoció durante un tiempo como Paseo Fernán Núñez. Hubo quien afirmó que la escultura de Ramón Bellver, El Ángel caído, colocada en un extremo del paseo, y que se presentó al público en la primavera de 1885, fue encargada y costeada por el III duque de Fernán Núñez a este artista, pero ha quedado demostrado documentalmente que ninguna de esas acciones se debieron al impulso de don Manuel. $^{2}$

Sí se ha escrito mucho sobre la actividad social, artística y cultural de los III duques de Fernán Núñez en Madrid, que fue intensa y brillante, especialmente en la segunda mitad del siglo XIX. Fueron mecenas y coleccionistas de arte, y en lo que se

\footnotetext{
${ }^{1}$ www.hemerotecadigital.bne.es. La Ilustración Española y Americana. 30/10/1874.

2 Alejandra Hernández Clemente, Ricardo Bellver y Ramón: su obra escultórica: un estudio historiográfico y documental (Madrid: Tesis, E-Prints Complutense, 2012).
} 
refiere a su vida pública, sobre todo en las fiestas que se celebraron en su residencia de la calle Santa Isabel, que se conocía hasta entonces como palacio de Cervellón. Tras la remodelación llevada a cabo en este edificio por el arquitecto Martín López Aguado, y ser decorado por el pintor y escenógrafo Joaquín Edo del Castillo, el palacio de Fernán Núñez podía rivalizar en lujo y esplendor con el resto de las casas nobiliarias de Madrid. $^{3}$

Según señala Inmaculada García Lozano, el famoso fotógrafo Jean Laurent Minier pudo ser requerido por los duques para fotografiar el palacio en su nuevo estado, o tal vez fue el propio fotógrafo el que solicitó permiso a los propietarios para poder hacer fotografías de las diferentes estancias de la residencia y comercializar con ellas. Como señala esta autora, la serie de 14 imágenes fueron publicadas en el catálogo titulado Nouvean Guide du Touriste en Espagne et Portugal. Itinéraire astístique, y para nosotros tienen mucho valor por la información que aporta sobre el aspecto del interior del palacio en aquel momento. ${ }^{4}$

Así por ejemplo, podemos ver la ubicación que tenían el retrato de Manuel Falcó, pintado por Rosales, ${ }^{5}$ y el de la duquesa, María del Pilar Osorio, obra de Madrazo, en el salón de retratos.

Como apunta José Antonio Vigara, ${ }^{6}$ la aristocracia madrileña supo utilizar las crónicas de sociedad de la prensa de la época para que quedase registro de bailes y cenas de gala, de la suntuosidad y decoración de los salones, de la novedad y lujo del vestuario o de la calidad de las joyas lucidas, acorde con el prestigio de los invitados. Todo ello obedecía a un programa de promoción social que resaltaba las señas de identidad de la clase nobiliaria de ese tiempo. La perpetuación de linajes, la ocasión de proyectar futuros enlaces familiares, la ostentación de arquitecturas y exhibición de colecciones de obras de arte, la promoción política o la importación de ideas y modas europeas, todo tenía cabida en esas reuniones selectas.

Por poner un ejemplo de descripción de este tipo de celebraciones, la noche del 27 de enero de 1885, los III duques de Fernán Núñez organizaron en su residencia

\footnotetext{
${ }^{3}$ Inmaculada García Lozano y Mario Sánchez Cachero (fot.). "El Palacio de Fernán Núñez, una joya por conocer del patrimonio arquitectónico y cultural madrileño", en La gatera de la Villa, no 22 (Madrid, año 2016), 37-52.

${ }^{4}$ Inmaculada García Lozano. "El palacio y la colección de los Duques de Fernán Núñez en imágenes. 1839-1939", en Actas I Jornadas sobre Investigación en Historia de la Fotografía. 1839-1939: Un siglo de fotografía. (Hernández Latas, José Antonio (ed.) 2017), 185-196. Imágenes custodiadas en el Archivo Ruiz Vernacci del IPCE (Instituto del Patrimonio Cultural de ESPAÑA) del Ministerio de Cultura, con los siguientes núms. de inventario: VN-10002, VN-01004, VN-04226, VN-04225, VN04224, VN-04228, VN-02984, VN-00996, VN-01001, VN-01005, VN-04099, VN-04097, VN-08816, VN-08820.

${ }^{5}$ Luís Rubio Gil, Rosales. El testamento de Isabel la Católica (Edición digital: Ediciones del Serbal, 2011), 44.

${ }^{6}$ José Antonio Vigara Zafra. "Los Fastos de los III duques de Fernán Núñez: nuevas políticas de construcción de la imagen nobiliaria en el siglo XIX", en Caiana. Revista de Historia del Arte y Cultura Visual del Centro Argentino de Investigadores de Arte (Buenos Aires: CALA. n 11, Segundo semestre, 2017), 69-83.
} 
la llamada Fiesta de Caridad, y que conocemos bien porque, al igual que otras de este tipo, fue reseñada con todo detalle en la prensa. ${ }^{7}$

Se calificaba entonces al palacio de Fernán Núñez como "rico museo de las Bellas Artes y archivo de gloriosas e imperecederas memorias históricas".

La fiesta se celebraba para recaudar fondos destinados a paliar la ruina que el terrible terremoto de la noche de 25 de diciembre de 1884 había ocasionado en numerosos pueblos de las provincias de Granada y Málaga.

Los duques contaron para esa memorable velada con la asistencia del rey Alfonso XII, de la reina María Cristina de Habsburgo-Lorena, y de las infantas doña María de las Mercedes y doña María Teresa. Para hacernos una idea de la organización de la fiesta, y siguiendo el relato que apareció en La Ilustración Española y Americana, se establecieron diversas actividades para recaudar fondos y al mismo tiempo deleitar a los ilustres invitados.

Por un lado, se vendieron ejemplares del número extraordinario del diario público El Día, a peseta cada uno; por otro, se celebró un concierto en el salón principal a cargo de "los artistas del teatro Real Sras. Theodorini y Pasqua y señores Battistini, Rapp y Baldelli, acompañados al piano por el profesor Sr. Pomé", con los Reyes e Infantas sentados en la primera fila, acompañados de señoras y de hombres "representantes de la nobleza, la política, las letras y las armas".

Se podían adquirir también billetes para una rifa, a peseta cada uno; e igualmente se podían comprar flores, pastas o copas de champagne en unos puestos distribuidos en los admirados Serre y Jardín de invierno del palacio, donde se llevó a cabo la citad rifa.

Finalmente, se podía degustar chocolate, a cuatro reales la taza, en la llamada Chocolatería Andaluza, ubicada en el comedor del invernadero. El resultado de la celebración fue un éxito a tenor de lo recaudado, ya que según se certificó en una carta de la Junta Popular de Socorros, se remitieron por parte del duque de Fernán Núñez, 6.000 duros para los damnificados de los pueblos de Granada y la misma cantidad para aquellos de la provincia de Málaga.

Esta forma de organizar y celebrar festejos, ${ }^{8}$ y gracias a las crónicas sociales, pronto se extendió fuera de nuestras fronteras y se imitó en París, de mano del propio III duque de Fernán Núñez cuando ejerció de embajador en dicha ciudad en 1881, e incluso en lugares tan lejanos como México.

Supieron adaptarse a las formas de diversión galante de la época isabelina, introduciendo los bailes de máscaras en los palacios durante el Carnaval, o la fórmula más original de reproducir trajes históricos para conformar los llamados cuadros vivientes o tableaux vivants, tan de moda en Europa, y que causaron furor en las casas nobiliarias. En ocasiones se proponía un tema a modo de código para un baile; por

\footnotetext{
${ }^{7}$ www.hemerotecadigital.bne.es. Ejemplares del título: La ilustración española y americana. 15/02/1885.

${ }^{8}$ Cristina del Prado Higuera, El Todo Madrid: La corte, la nobleza y sus espacios de sociabilidad en el siglo XIX (Madrid: Fundación Universitaria Española, 2013), 112-113.

${ }_{9}$ Clementina Díaz y de Ovando, Invitación al baile. Arte, espectáculo y rito en la sociedad mexicana (18251910) (México, UNAM, 2006, vol. II), 589-592.
} 
ejemplo, en 1862 fue el de don Quijote de la Mancha, y en 1863 se propuso el de la época de Isabel la Católica. ${ }^{10}$

Al mismo tiempo, se pusieron de moda las llamadas tarjetas de visita, confeccionadas por fotógrafos contratados por los anfitriones de estas fiestas para retratarles con esos disfraces, trajes de época o formando composiciones que imitaban lienzos con asuntos de historia. Los duques de Fernán Núñez, por ejemplo, contrataron para ello los servicios de los fotógrafos Ángel Alonso Martínez o Pedro Martínez de Hebert. Se solían confeccionar con ese material álbumes ricamente encuadernados para los duques o para obsequiar a algunos de sus invitados más ilustres, como fue el caso de la Familia Real. ${ }^{11}$

Otras dos intervenciones del III duque de Fernán Núñez vamos a resaltar: la construcción del panteón neogótico en La Alameda, y el encargo al ingeniero Eugenio Barrón Avignón, de un estacado y dique en el tramo del río Jarama correspondiente al Soto del Malecón, perteneciente a la villa de Barajas.

En cuanto al proceso que condujo a la construcción del panteón, es necesario referirse al cementerio extramuros que diseñó para la villa de Fernán Núñez, en Córdoba, el VI conde de este título, don Carlos José Gutiérrez de los Ríos y RohanChabot. ${ }^{12}$ Como señala Vigara, en enero de 1786 se presentó la tasación del proyecto a cargo del maestro de obras José Díaz de Acevedo, aunque el plano definitivo se hizo justo un año después, en enero de 1787, iniciándose en ese mismo año las obras, si bien no se finalizó como lo había diseñado don Carlos José.

Con el paso del tiempo, y debido a diferentes circunstancias, hacia 1818 el camposanto presentaba un preocupante estado de abandono, próximo al estado de ruina. Se quiso construir uno nuevo en 1858 por impulso del Ayuntamiento de Fernán Núñez, pero sin contar con el III duque de Fernán Núñez, por lo que hubo un pleito con el consistorio en el que se planteó también el tema de erigir en un lugar preferente del nuevo cementerio su panteón familiar (la información que a este respecto aporta Vigara en el artículo citado es muy detallada).

Debido a que esa condición no se iba a respetar, el III duque de Fernán Núñez no quiso ser partícipe en este proyecto, y fue cuando en 1879 le encargó al arquitecto Francisco de Cubas y González, marqués de Cubas, el hermoso panteón que estaría

\footnotetext{
${ }^{10}$ Cristóbal Marín Tovar y Virginia Tovar Martín, El Palacio Parcent (Madrid: Ministerio de Justicia, 2009).

Vicente Sancho del Castillo. Baile de trajes en casa de los duques de Fernán Núnez: 25 de febrero de 1884 / apuntes tomados por Vicente Sancho del Castillo y Emilio Bravo y Moltó (Madrid: Imprenta y esterotipia de El Liberal).

${ }^{11}$ El álbum titulado "Retratos de S.M. la reina Isabel II, Duques de Montpensier y otros personajes de la época, con trajes fantásticos e históricos en el baile de trajes de Fernán Núñez" se conserva en Patrimonio Nacional. Biblioteca Real, con signatura FOT/231. Cita recogida en García Lozano, Inmaculada. Ob. cit.

${ }^{12}$ José Antonio Vigara Zafra. "El cementerio Neoclásico del VI Conde de Fernán Núñez: Un ejemplo de distinción social y apropiación del espacio funerario", en Laboratorio de Arte (Sevilla: $\mathrm{n}^{\circ} 28$ (2016), 433-454.
} 
ubicado en su posesión de La Alameda, en Madrid, y que fue bendecido el 25 de noviembre de $1883 .^{13}$

A esa idea de erigir un mausoleo familiar en Madrid, contribuyó la intención de que fuese depositado en él el cuerpo de la hija de los duques, doña Isabel Falcó y Osorio, que falleció en Málaga el 8 de mayo de 1875 a los dieciséis años de edad, y había sido sepultada en aquella ciudad. Su cuerpo fue trasladado al nuevo panteón el día 27 de abril de 1884, siendo el primero de los de la familia que reposarían en este lugar, donde también hallarían cristiana sepultura entre otros, su padre, don Manuel Falcó, fallecido en su posesión La Flamenca de Aranjuez, el 24 de mayo de $1892,{ }^{14}$ y años después su madre, doña María del Pilar Osorio, que falleció el 1 de septiembre de 1921 en la localidad belga de Namur.

La duquesa de Fernán Núñez ostentaba también los títulos de XIII condesa de Barajas y XII marquesa de Alameda, por lo que tanto ella como su marido, a través de sus administradores, estaban al tanto de los problemas que amenazaban sus propiedades en aquellos lugares, y tomaron las medidas necesarias para que se llevasen a cabo los remedios pertinentes.

Los señores y los condes de Barajas ya eran dueños en el siglo XV de una serie de aldeas y tierras en esa localidad a orillas del río Jarama, como eran Torrejoncillo o Torrejón de la Ribera. La actividad principal en esos lugares era la agricultura, seguida de la ganadería, la caza, la pesca y otra serie de trabajos relacionados con la explotación de dos molinos harineros y dos hornos.

Los problemas surgían cuando se producían grandes crecidas o avenidas destructivas del río Jarama, fuera de lo que eran los ritmos fluviales normales que se daban a lo largo del año, ya que estos fenómenos afectaban seriamente a cultivos, instalaciones hidráulicas, construcciones, ganado, etc. ${ }^{15}$

Se han llevado a cabo interesantes estudios que analizan los índices de precipitaciones en una zona geográfica concreta, para determinar las avenidas fluviales que pueden producirse como consecuencia de éstas, teniendo en cuenta factores como la situación del terreno, la deforestación, el recorrido del cauce del río, etc. En el caso del río Jarama, y para una horquilla temporal que va del siglo XVI al XVIII, se puede determinar que los periodos en los hay un mayor riesgo de aumento extraordinario del caudal del río, y que a causa de ello se produzcan avenidas destructivas, se sitúan en dos momentos al año: uno en los meses de invierno, sobre todo si se han producido

${ }^{13}$ Carlos Saguar Quer, Arquitectura funeraria madrileña del siglo XIX (Madrid: Universidad Complutense, 1989).

${ }^{14}$ www.hemerotecadigital.bne.es. Ejemplares del título: La ilustración española y americana. 30 de mayo de 1892. Sobre la muerte del III duque de Fernán Núñez, señala que su figura destacaba "por el fausto de su casa, la brillantez de sus fiestas, su cortesía, su noble y arrogante figura, sus trenes y su magnífica cuadra de caballos de carrera".

15 Teresa Bullón Mata, "Avenidas fluviales y precipitaciones en las cuencas de los ríos Jarama-Tajo al final del siglo XVI", en Boletín de la Asociación de Geógrafos Españoles (Madrid: nº 60, 2012), 77-90. 
precipitaciones de lluvia y nieve, y otro en primavera, entre los meses de marzo y mayo, coincidiendo con el deshielo. ${ }^{16}$

Hay que tener siempre en cuenta el peligro que suponían las llamadas flash floods, que se corresponden con fuertes precipitaciones que se suelen dar en periodos estivales, que son difíciles de predecir, generalmente de poca duración, pero de una intensidad elevadísima, y con un poder destructivo asombroso.

En los lugares susceptibles de ser anegados cuando se producían estos fenómenos, lo habitual en aquella época era levantar una estacada o construir pequeñas presas y diques para frenar la velocidad y la capacidad destructiva de las aguas, formando al mismo tiempo espacios para la reserva de agua que podría ser destinada al riego. ${ }^{17}$

Toda la zona del Jarama del entorno de Barajas ha resultado ser muy rica en yacimientos arqueológicos, y concretamente la del Malecón se corresponde con restos pertenecientes a la Edad del Hierro. Estos descubrimientos se han ido produciendo a consecuencia de los sucesivos trabajos de ampliación del aeropuerto de Madrid-Barajas Adolfo Suárez, y la asociación cultural Barajas BIC se ha encargado de informar sobre las excavaciones y de comentar la importancia de los diferentes hallazgos. ${ }^{18}$

Para hacernos una idea de las fincas y derechos que componían el Estado de Barajas en el siglo XIX, y que estaban comprendidas en el mencionado apeo del año 1747, contamos con una descripción de las mismas en un documento fechado el 10 de septiembre de 1813, ante el escribano de Barajas, don José García de la Puente. ${ }^{19}$

Serían unas 175 parcelas, arrendadas todas a vecinos de Barajas y la Alameda, así como diferentes huertas, como las llamadas El Callejón, El Cermeño o El Estanque, todas ellas igualmente arrendadas. ${ }^{20}$

Ya en 1803 se habían hecho mediciones y delimitaciones de parcelas singulares, realizadas por el geómetra y agrimensor don Juan Ramón de las Heras a petición de don Cayetano Humarán de Aragón, administrador de los Estados de Barajas. ${ }^{21}$ Otra medición parecida se hizo en 1817, firmada por Antonio María Pérez. ${ }^{22}$

Ya hemos comentado que, a orillas del Jarama, en los términos de Torrejoncillo y Torrejón de la Ribera, pertenecientes al Estado de Barajas, existían dos molinos harineros que aprovechaban el caudal de las aguas y contaban con unas presas, pero

\footnotetext{
16 Teresa Bullón Mata, "Morfología fluvial del río Jarama entre los siglos XVI y XIX. Datos documentales y cartográficos", en Temas y lugares (recurso electrónico: homenaje a Eduardo Martínez de Pisón/coord. por María Eugenia Arozena Concepción, Carmen Romero Ruíz, 2016), 77-94.

17 Francisco Fernández Izquierdo, Ángel Alloza Aparicio y Francisco Javier Moreno Díaz del Campo, La Presa del Vado y el Canal del Jarama. (Madrid: Proyecto de investigación. Fundación Canal. Canal de Isabel II, 2016).

18 AA.VV. Barajas. Cuatro mil años de historia a través de la arqueología. Propuesta para la puesta en valor del patrimonio arqueológico del distrito de Barajas. Barajas, distrito BIC (recurso digital), 2018

${ }^{19}$ Archivo Histórico de la Nobleza, Fondo Fernán Núñez (AHNOB. FN) Leg. 734/36.

${ }^{20}$ AHNOB. FN Leg. 199/3.

21 AHNOB. FN Leg. 734/28 n 1 Tierras de sembradura en el Jarama. 25 de enero de 1803; AHNOB. FN Leg. $734 / 28$ nº 2.

${ }^{22}$ AHNOB. FN Leg. 734/28 no 2 Tierra no 147 del apeo de 1747 que posee el Condado de Barajas junto a las Eras del Concejo.
} 
que tuvieron que ser constantemente reparados por los daños que sufrían a causa de crecidas anormales del río.

Solo a modo informativo, referimos a continuación algunas fechas en las que fue necesario hacer intervenciones en estos molinos, y que sirven de ejemplo de las cuantiosas inversiones monetarias que se tuvieron que hacer para que funcionasen de forma óptima.

En 1562, Francisco Zapata de Cisneros, que será conde de Barajas desde 1572, invirtió varios miles de ducados para reparar y fortalecer el molino de Torrejoncillo. ${ }^{23}$ En el periodo que va entre 1597 y 1602 el molino estaba ya estaría reparado porque fue objeto de varios arrendamientos. ${ }^{24}$

Junto a los molinos harineros, el conde de Barajas tenía arrendados en Torrejoncillo un horno grande y otro pequeño para hacer ladrillos y tejas, ${ }^{25}$ lo que da idea de la importancia de la actividad económica de ese lugar, y de los ingresos que generaban; por eso le interesaba a los Zapata que molinos, hornos, además de huertas y tierras de sembrado, permaneciesen en perfecto estado para cumplir con sus funciones.

El 30 de septiembre de 1624 se firmó una escritura por la que el maestro de obras de presas de río Josephe Díaz, vecino de la villa de Algete, se obligaba en favor del conde de Barajas y de Bernardo Calderón, su mayordomo, en su nombre, para aderezar la presa que tenía en el río Jarama, jurisdicción de su villa de Torrejón de la Ribera para el servicio de los molinos y huertas de ese término. ${ }^{26}$ La presa había sido muy dañada por una avenida del río, que había destruido entre 18 y 20 maderos que debían ser sustituidos por estacas de madera de álamo, que se podrían cortar de los árboles que crecían en la orilla del río, y así contener las aguas. Para los molinos, entre otra serie de condiciones de obra, se debían colocar vigas de madera y restituir las piedras removidas para reparar el caz de los mismos.

Los molinos necesitaron nuevas intervenciones en julio de $1641,{ }^{27} \mathrm{y}$ en agosto de 1670, el maestro de obras Manuel Sánchez y sus oficiales estaban trabajando en el caz de los molinos para componerlos. ${ }^{28}$

El periodo estival parecía el más adecuado para realizar las obras en los molinos, porque justo los días 29 y 30 de agosto de 1674, el maestro de obras de presas Andrés de Lillo, vecino de la villa de Alcalá de Henares, hizo aderezo y reparos en la misma presa de Torrejón de la Ribera para sustituir estacas y recolocar piedras que estaban derrumbadas. ${ }^{29}$

\footnotetext{
${ }_{23}$ Archivo Histórico de Protocolos de Madrid (AHPM), Po 400, ff. 289-295v; ff. 300-300v y ff. 434438v.

${ }^{24}$ AHNOB. FN Leg. 357/31.

${ }^{25}$ En 1604 tenemos noticias de arriendo del horno grande (AHNOB. FN Leg. 866/31), y en 1606 se acordó otro arrendamiento, pero referido al horno pequeño (AHNOB. FN Leg. 395/7 n⿳ 32)

${ }^{26}$ AHNOB. FN Leg. 423/67.

${ }^{27}$ AHNOB. FN Leg. 395/7 no 32, 6 de julio 1641.

${ }^{28}$ AHNOB. FN Leg. 395/7 n o 25, 23 de agosto 1670.

${ }^{29}$ AHNOB. FN Leg. 741/14, 29 de agosto y leg. 741/14 nº 6, 30 de agosto 1674.
} 
El día del Corpus del año 1684 se produjo una avenida muy destructiva del Jarama, que dañó seriamente la presa de los molinos en Torrejón de la Ribera. Se hizo una amplia relación de todos los materiales que sería necesario adquirir para volver a dejar todo de nuevo en funcionamiento, y con una serie de refuerzos para prevenir este tipo de fenómenos tan demoledores.

Además, a lo largo de los años, y a causa de las constantes avenidas, se habían ido acumulando arenas y piedras arrastradas por el caudal del río, formando una gran isla e isleta en el ramal del río que bañaba de un lado tierras del término de Paracuellos, y de otro, fincas pertenecientes al Estado de Barajas, propiedad ahora de los duques de Fernán Núñez. Las aguas fueron buscando otras vías por las que discurrir, apareciendo varias ramificaciones que dañaban considerablemente los terrenos circundantes cuando se producían las crecidas.

Los problemas en el Jarama fueron motivo de preocupación también en el siglo XIX. Ya en 1800 se hicieron informes de los daños causados por el Jarama en las heredades del conde de Barajas. ${ }^{30}$

El 31 de agosto de 1815 quedó en pasar un arquitecto por la zona para revisar daños en la presa del Jarama en el Malecón, y hacer informe en el que determinar el número de cestas necesario para la contención de las aguas, y sobre el grueso y longitud que deberían tener las estacas para sustituir a las quebradas. ${ }^{31}$

Tres años más tarde, en 1818, un ganadero avisó del deterioro que presentaba la presa hecha en el Soto del Malecón a orillas del Jarama, a consecuencia de una crecida violenta. La explotación de estas tierras y huertas suponía una fuente importante de ingresos para sus propietarios, tal y como demuestran las escrituras de arrendamiento que se conservan, por lo que era necesario ejecutar las intervenciones que fuesen necesarias para que los arrendatarios pudiesen realizar sus actividades de forma segura, para satisfacción de ambas partes. ${ }^{32}$

Si hacemos un pequeño salto temporal, llegamos a otro momento de gran destrucción e inundación, que se produjo en 1856, y que fue la razón para que en 1860 el III duque de Fernán Núñez tomase medidas contundentes para fortificar esa ribera del Jarama. Se trata de un proyecto que hemos localizado en el Archivo Histórico de Nobleza, firmado por el director de Caminos Vecinales, José Ramón de Eguía Madariaga y por el ingeniero de Caminos, Canales y Puertos, Eugenio Barrón Avignón. ${ }^{33}$ El planteamiento consistía en colocar un estacado y levantar un dique para sustituir a la construcción anterior que había sido destruida. ${ }^{34}$

No ha sido bien estudiada la figura de José Ramón de Eguía Madariaga (UgaoMiraballes 1823-Madrid, 12 de febrero de 1879). Carmen Castells indica que este arquitecto vizcaíno había obtenido el título de maestro de obras en la Academia de

30 AHNOB. FN Leg. 730/3.

${ }^{31}$ AHNOB. FN Leg. 730/3, 31 de agosto 1815.

32 AHNOB. FN Leg. 740/6.

33 AHNOB. FN Leg. 734/2. Papeles concernientes a unas empalizadas y obras de defensa proyectadas para impedir la socavación de los terrenos del Soto del Malecón en la ribera del río Jarama. Año 1860

34 AHNOB. FN Leg. 734/2. 
Bellas Artes de San Fernando, y también el de director de Caminos Vecinales, cargo con el que firma los proyectos que luego presentaremos. ${ }^{35}$

Por su parte, Eugenio Barrón Avignón, que como hemos señalado al principio, trabajó en la conformación del Paseo de Carruajes del Parque del Retiro en 1874, era bien conocido. Barrón nació en París en 1820 y falleció en Madrid el 5 de mayo de 1882. Como hemos señalado, consiguió el título de ingeniero de Caminos, Canales y Puertos. $^{36}$

Fueron muchas las obras que podríamos destacar a lo largo de su trayectoria. Él fue el creador del primer puente colgante que se hizo en Andalucía, concretamente en la localidad de Mengíbar, sobre el río Guadalquivir, que fue inaugurado en 1845 y dejó de estar en activo en 1930; o la reparación del puente colgante de Arganda en $1862 .{ }^{37}$

En lo que respecta a la red de carreteras que se estaba creando en España, Barrón realizó unas aportaciones fundamentales a través de su artículo, fechado el 1 de diciembre de 1861, titulado "Del asfalto y sus aplicaciones", y que fue publicado en la Revista de Obras Públicas, como señala Juan Antonio Becerril Bustamante. ${ }^{38}$

En Madrid desarrolló diversas actividades, como las ejecutadas en los desmontes de la plaza de Santa Bárbara y las rondas contiguas, o la prolongación de la calle Princesa en la zona de Argüelles. ${ }^{39}$ Pero sin duda destacó por su singularidad el viaducto de hierro que proyectó sobre la calle Segovia, con el que se salvaba el profundo desnivel de terreno que existía entre el palacio Real y las Vistillas, prolongando así la calle Bailén hasta San Francisco el Grande. El arquitecto Sachetti ya había presentado un proyecto en el siglo XVIII para hacer un puente en este mismo lugar, pero fue el de Barrón el que se ejecutó finalmente, manteniéndose en uso desde su inauguración en 1874, hasta que fue derribado en 1932. En la Revista de Obras Públicas publicó este ingeniero dos artículos explicando el planteamiento de estas obras en la zona de la calle Bailén. ${ }^{40}$

35 Carmen Castells, Eguía Madariaga, José Ramón De (Auñamendi Entziklopedia [on line], 2019) http://aunamendi.eusko-ikaskuntza.eus/eu/eguia-madariaga-jose-ramon-de/ar-37235/ (consultado el 25 de enero de 2019).

${ }^{36}$ Fernando Sáenz Ridruejo. "Datos para el estudio sociológico del cuerpo de ingenieros de caminos a mediados del siglo XIX", en Actas II Congreso de la Sociedad Española de Historia de las Ciencias. (Madrid: Vol. 2, 1984), 361-378.

37 Mariano Serrano Pascual. "Romper con las tradiciones. Más allá del arco, puentes para la modernidad, en la Arquería del Ministerio", en Revista del Ministerio de Fomento (Madrid: n 659, 2016), 44-47.

38 Juan Antonio Becerril Bustamante. "Siglo y medio de innovaciones en la construcción: la ingeniería civil española a través de la Revista de Obras Públicas", en Informes de la Construcción (Madrid: Vol. 60, 510, págs. 7-34, abril-junio 2008). El artículo de Eugenio Barrón se publicó en la citada Revista de Obras Públicas en 1861, tomo I, nº 23, págs. 283-286.

${ }^{39}$ Eulalia Ruíz Palomeque, Ordenación y transformaciones urbanas del casco antiguo madrileño durante los siglos XIX y XX (Madrid: Instituto de Estudios Madrileños, 1976).

${ }^{40}$ Eugenio Barrón Avignón. "Madrid: Prolongación de la calle de Bailen y puente de hierro para la de Segovia", en Revista de Obras Públicas (Madrid: 1861, 9, tomo I, n 18), 217-224; y con el mismo título, (Madrid: 1861, 9, tomo I, n¹9), 229-233. 
Eugenio Barrón fue también Senador por la provincia de Huesca durante la legislatura 1879-1880. En la hoja de servicios que presentó para acceder a este cargo, refirió su trayectoria profesional y nombramientos a lo largo de cuarenta años, desde el 26 de octubre de 1835, cuando era alumno de la Escuela, hasta el 21 de febrero de 1879, cuando fue nombrado Inspector General de Primera Clase, con sueldo de 40.000 reales de vellón. Es en ese momento cuando pasó a ser Senador. ${ }^{41}$

En el mes de mayo o primeros días de junio de 1860, un dibujo que estimamos de mano de Barrón, sirvió de base para que el 4 de junio de ese mismo año, el carpintero don Juan Comas y Pi presentase un presupuesto "para la mano de obra y materiales de un tabla (sic) y estacado que se ha de construir en el río Jarama para resguardo de la propiedad del Duque de Fernán Núñez en el lugar llamado el Malecón, en el Pueblo de Barajas".42

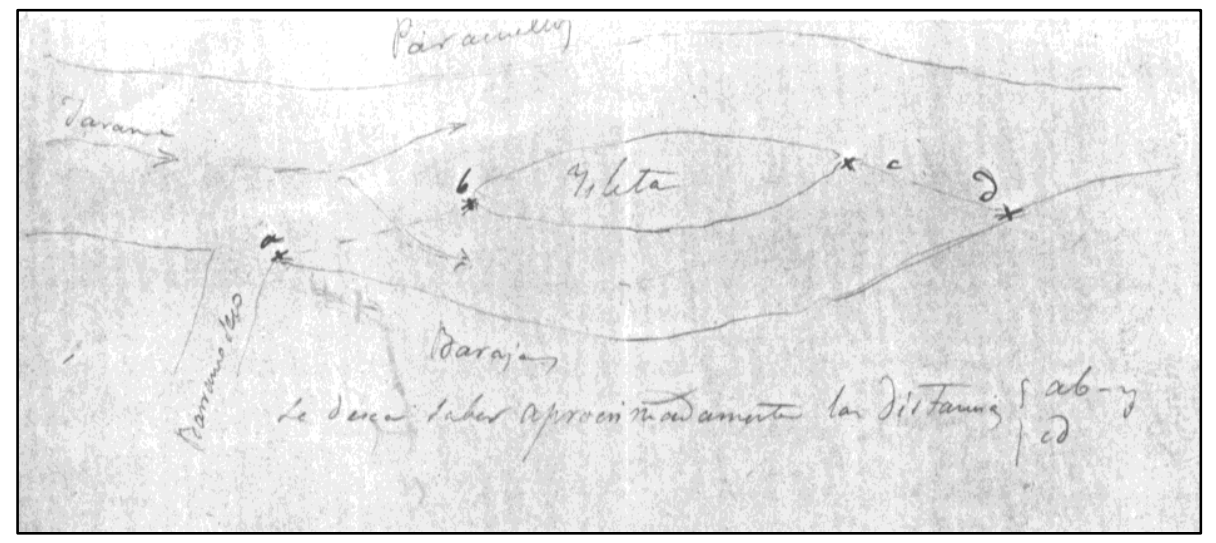

Fig. 1 - E. Barrón, Dibujo de la isleta en el río Jarama entre tierras de Paracuellos y Barajas. 1860, AHNOB. FN Leg. 734/2 nº 27.

Además de los numeroso materiales que aparecen en la relación que presenta, indica el importe del pago de catorce obreros, aparejador y constructor, por diez semanas de trabajo. La suma de todas las partidas da una cantidad de 31.250 reales. Se aconseja aprovechar la retama de los árboles más grandes para formar el tejido entre las estacas (se habían encargado 500 estacas de 7 metros de largo y 14 centímetros de grosor cada una).

Igualmente se solicitaba, si fuese posible, trabajar de día y de noche "para su pronta conclusión y salir de la posesión" en caso de que se produjese una riada.

En base al dibujo de Eugenio Barrón, Carlos García Llaguno, apoderado del duque de Fernán Núñez, dirige el 12 de julio una carta al Gobernador Civil de la Provincia en la que expone que a consecuencia de la última avenida del río Jarama, se había desbaratado el dique o estacada que existía, y se había originado un nuevo cauce

41 Expediente personal del senador D. Eugenio Barrón Avignón, por la provincia de Huesca. www.senado.es/web/conocersenado/senadohistoria/senado18341923/senadores/fichasenador/inde x.html?id1 $=323$.

42 AHNOB. FN Leg. 734/2 no 31 y no 32,4 de junio 1860. 
que dividía las tierras del Soto del Malecón, propiedad del duque de Fernán Núñez, por lo que además de separar las aguas de su cauce natural, causaba al propietario perjuicios de consideración.

Para evitar esos daños, continúa la carta, el duque ha determinado volver a construir el mencionado dique con arreglo al croquis del ingeniero Eugenio Barrón, pero como por la Real orden de 29 de octubre de este año, comunicada por el Ministerio de Fomento el 7 de mayo del mismo año, en su artículo 22, se exige que para la ejecución de estas obras se cuente con autorización del Gobernador de la Provincia bajo la inspección del ingeniero de la misma, le solicita por la presente carta que se le otorgue la pertinente licencia para ejecutar las expresadas obras. ${ }^{43}$

Para ayudar a agilizar los trámites de la licencia, el día siguiente, 13 de julio, escribe el apoderado del duque de Fernán Núñez al duque de Sesto, don José Osorio y Silva, que en ese momento era Alcalde de Madrid, para que interviniese a favor de don Manuel Falcó ante el Gobernador Civil en el asunto de la licencia para el dique. ${ }^{44}$ Le pide que sea rápido el despacho por ser el verano la mejor estación para realizar las obras.

Entre el 12 y el 16 de julio se volvieron a elaborar unos presupuestos, pero más detallados, para la obra, pormenorizando el jornal de carpinteros, peones, albañiles o aparejador; hay especial cuidado en todo lo relativo a la calidad de las maderas que se tenían que emplear y sus precios. Algunas se encontraban en el depósito de Aranjuez, y habría que traerlas por ferrocarril; otras podían comprarse en los almacenes de Los Catalanes, en la Puerta de Santa Bárbara, en el de La Aurora en la calle Embajadores, o en el de Los Belgas en la calle de Atocha, entre otros. ${ }^{45}$

Hay que señalar que en esas mismas fechas se le hicieron dos encargos más al carpintero Juan Comas y Pi, y que debía ejecutar una en el Malecón y otra en la casa del duque en Barajas. Es por ello por lo que algunas de las condiciones que se describen para las maderas, los precios, almacenes, etc. pueden referirse también a estos dos últimos proyectos, ya que a veces no queda claro el destino de los citados materiales en algunos de los documentos.

Uno de los trabajos era el de levantar o reparar un recinto con ocho jaulas nuevas en el Soto del Malecón, que contaría con un patio, pesebres y una casa para el pastor del ganado que iba a ser ubicado en dichas jaulas, tal y como figura en el dibujo que aportamos. ${ }^{46}$

\footnotetext{
${ }^{43}$ AHNOB. FN Leg. 734/2 nº 2 y no 27, 12 de julio 1860.

44 AHNOB. FN Leg. 734/2 n 28 y n n $^{\circ} 29,13$ de julio 1860.

45 AHNOB. FN Leg. 734/2 no 21 y no 33 a no 38, 12 a 16 de julio 1680.

${ }^{46}$ AHNOB. FN Leg. $734 / 2 \mathrm{n}^{\circ} 1$.
} 


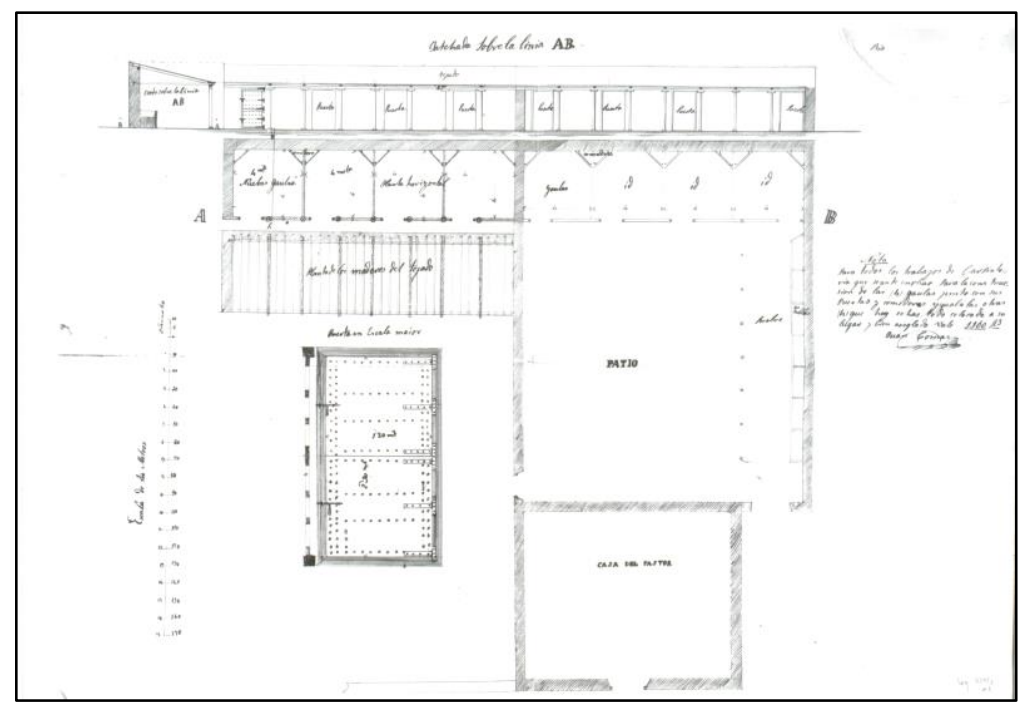

Fig. 2 - Juan Comas. Plano de las nuevas jaulas construidas en el Malecón o Soto de Barajas. Se trata de 8 jaulas, con patio, pesebre y casa del pastor. 1860, AHNOB. FN 734/2 nº 1.

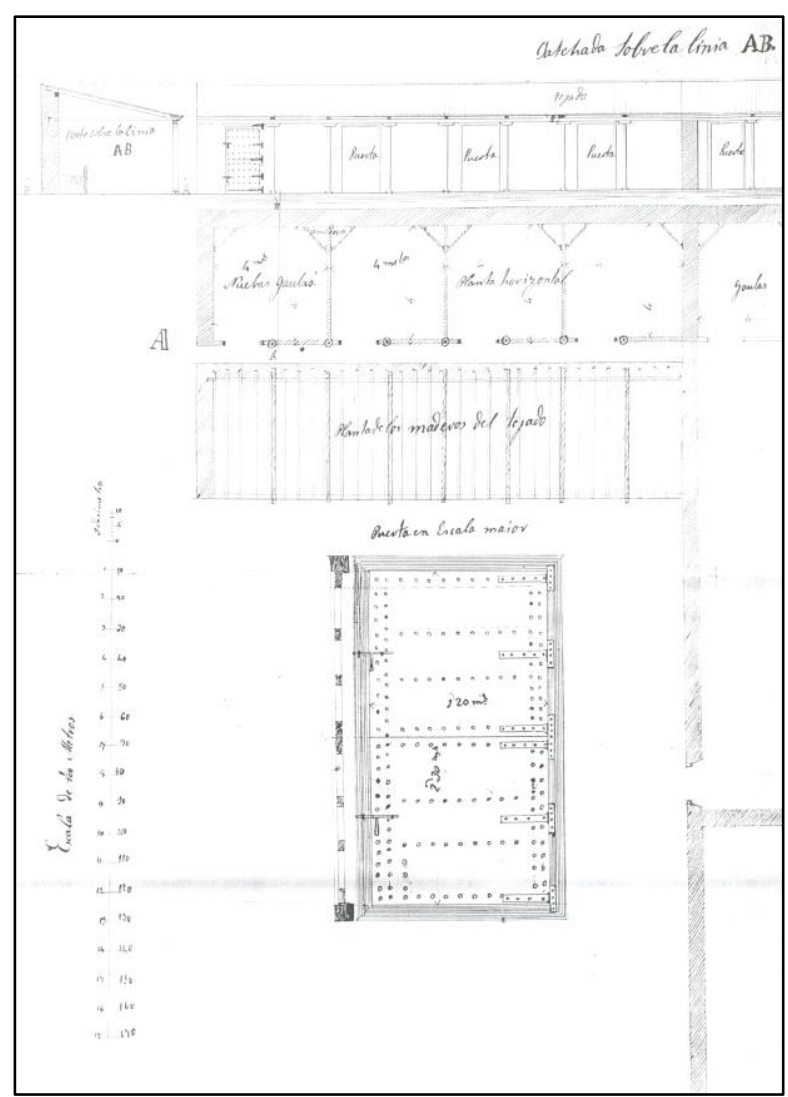

Fig. 3 - Juan Comas. Detalle del plano de las nuevas jaulas. 1860. AHNOB. FN 734/2 nº 1. 
El otro encargo era el de levantar un cenador para el jardín de la casa de Barajas, del cual tenemos un presupuesto firmado por Juan Comas en Madrid, el 11 de julio de $1860,{ }^{47} \mathrm{y}$ tres dibujos. Aunque presumimos que el seleccionado fue el que contiene además una relación de materiales y precios, hecho seguro por Juan Comas y Pi, pensamos que es interesante reproducir los otros dos dibujos. ${ }^{48}$

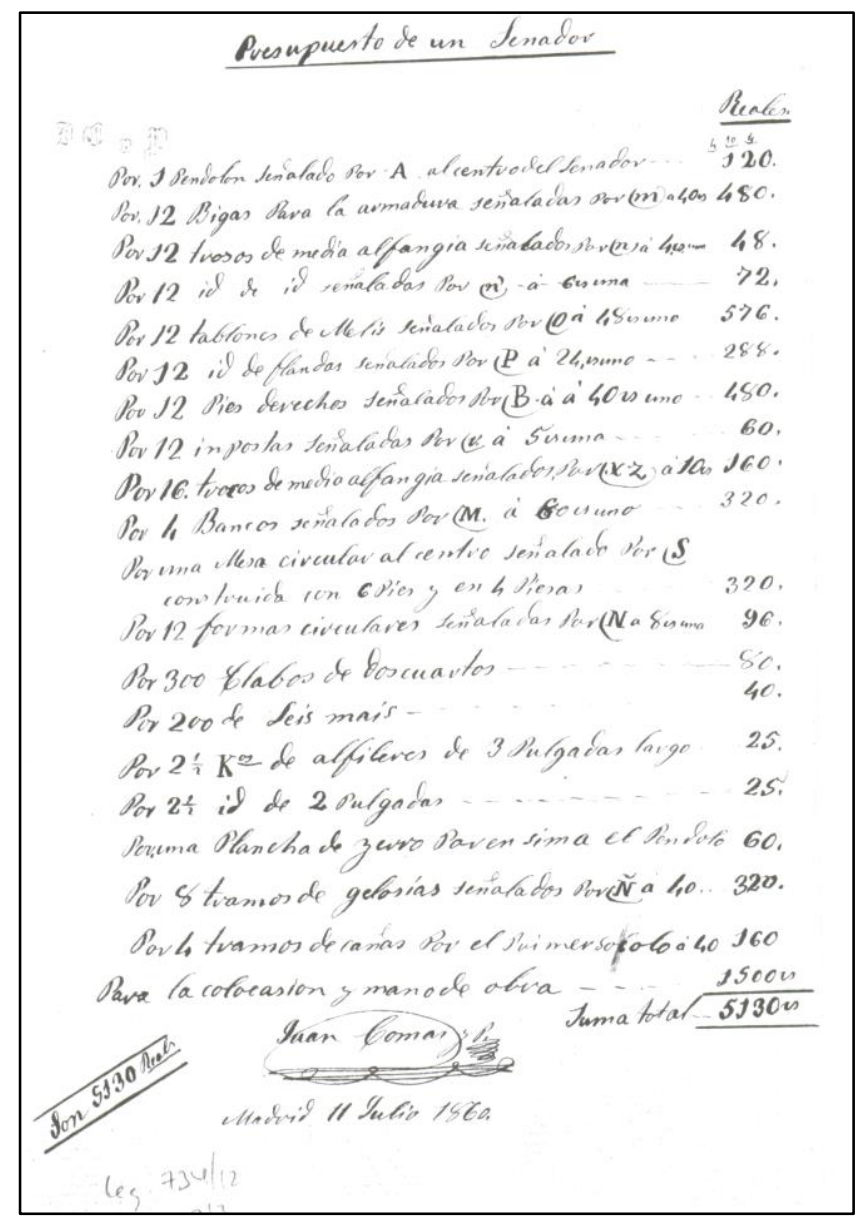

Fig 4 - Juan Comas Presupuesto de un cenador. Madrid, 11 de julio de 1860. AHNOB. FN $734 / 12 \mathrm{n}^{\circ} 13$.

47 AHNOB. FN Leg. 734/12 n 13, Madrid 11 de julio 1860.

48 AHNOB. FN Leg. 734/2 n 2 y nº 6, Madrid 5 de septiembre 1860. 


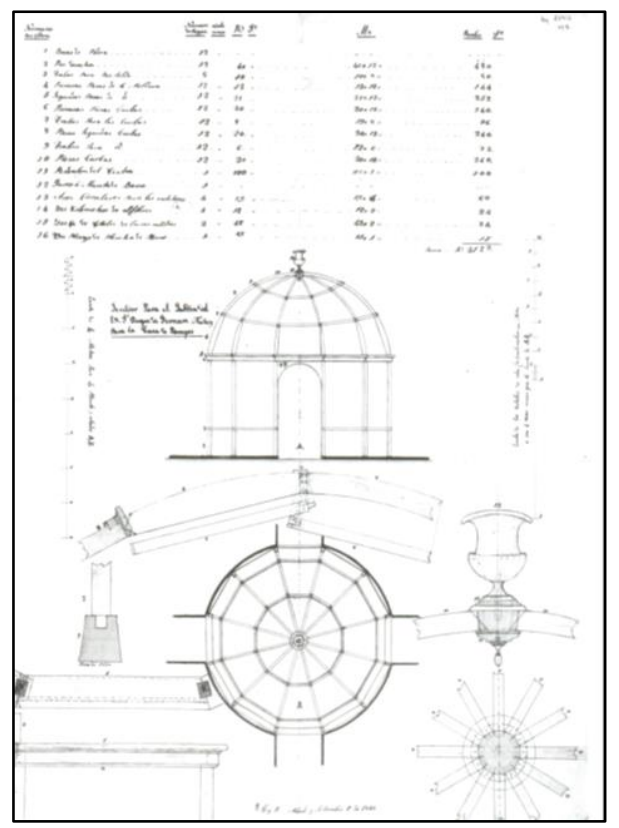

Fig. 5 - Juan Comas y Pi. Cenador para el jardín del Ex. Sr. Duque de Fernán Núñez para la casa de Barajas. Madrid, 5 de septiembre de 1860, AHNOB. FN Leg. 734/2 nº 2.

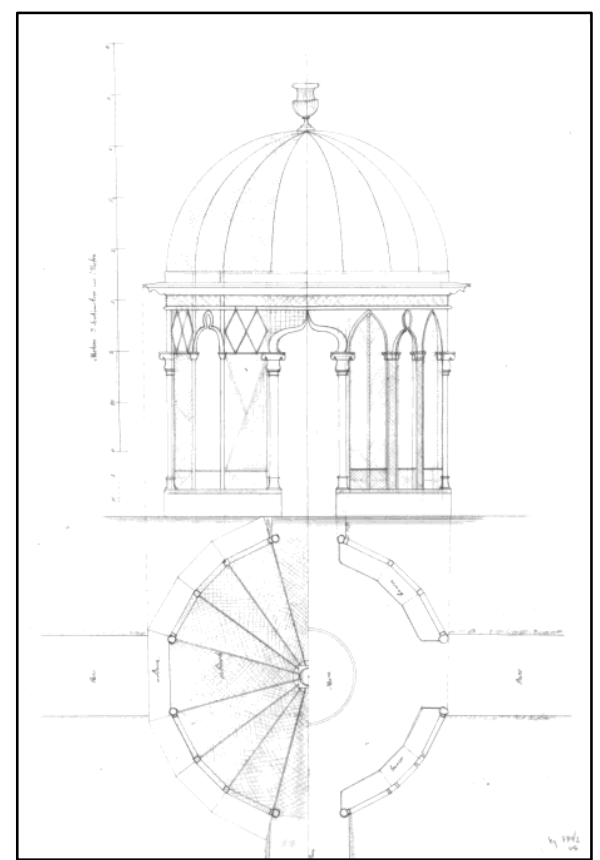

Fig. 6 - Sin firma. Proyecto para un cenador. Hacia 1860, AHNOB. FN Leg. 734/2 nº 6. 


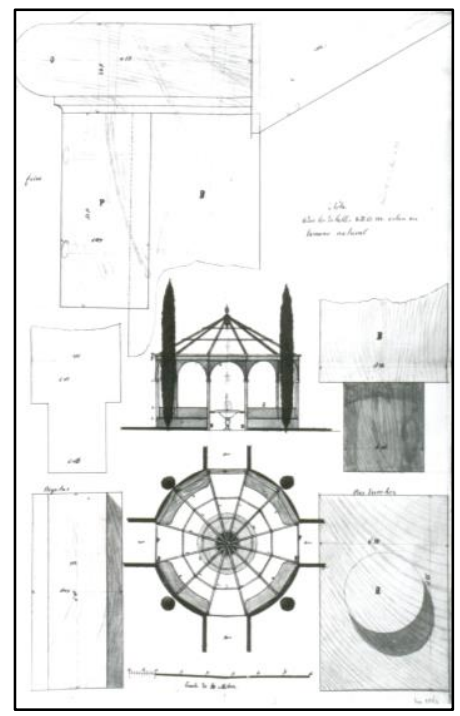

Fig. 7 - Sin firma. Proyecto para un cenador con fuente. Hacia 1860, AHNOB. FN Leg. 734/2.

Tenemos además otro presupuesto y una serie de dibujos para levantar un velador y bancos para el cenador en el jardín de Barajas, fechados el 24 de octubre de 1860 en dicha villa de Barajas. ${ }^{49}$ Se detalla que se tenían que hacer con cañas naturales.

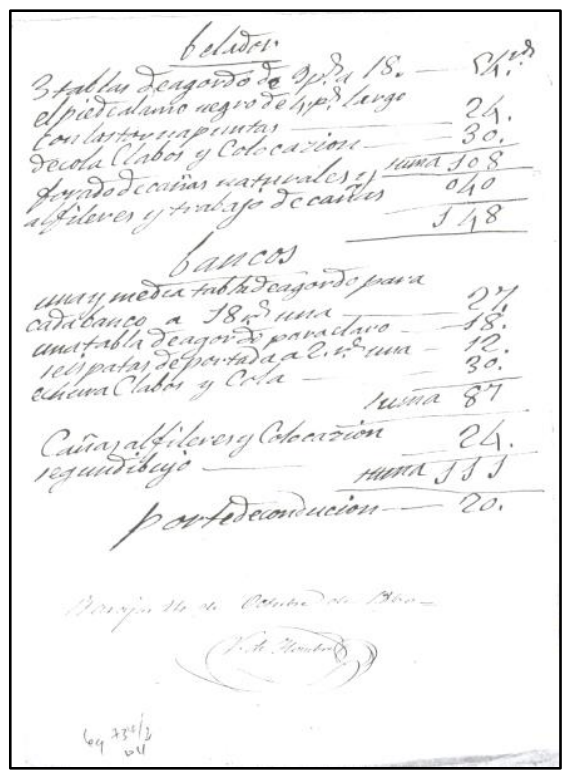

Fig. 8-Vicente de Hombre. Presupuesto para un velador y bancos para el cenador en el jardín de Barajas. Barajas, 14 de octubre de 1860. AHNOB. FN Leg. 734/2 no 6.

${ }^{49}$ AHNOB. FN Leg. 734/2 no 4, 8 y 9. Los bancos y el velador, de cuatro pies de diámetro, serían de cañas naturales. Firma el presupuesto V. de Hombre. 


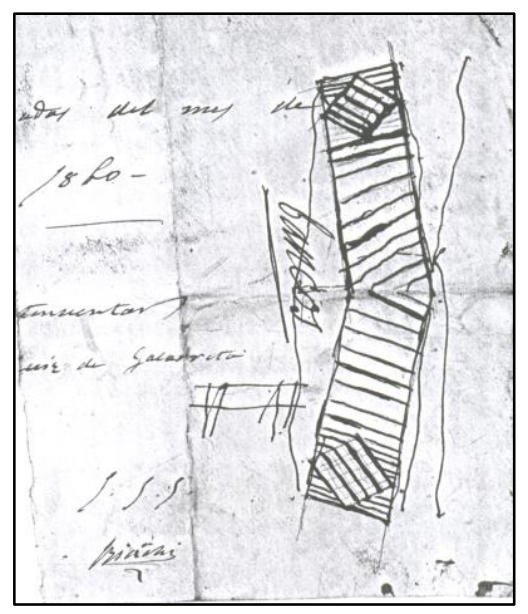

Fig. 9- Dibujo para un banco. 1860, AHNOB. FN Leg. 734/2 nº 6.

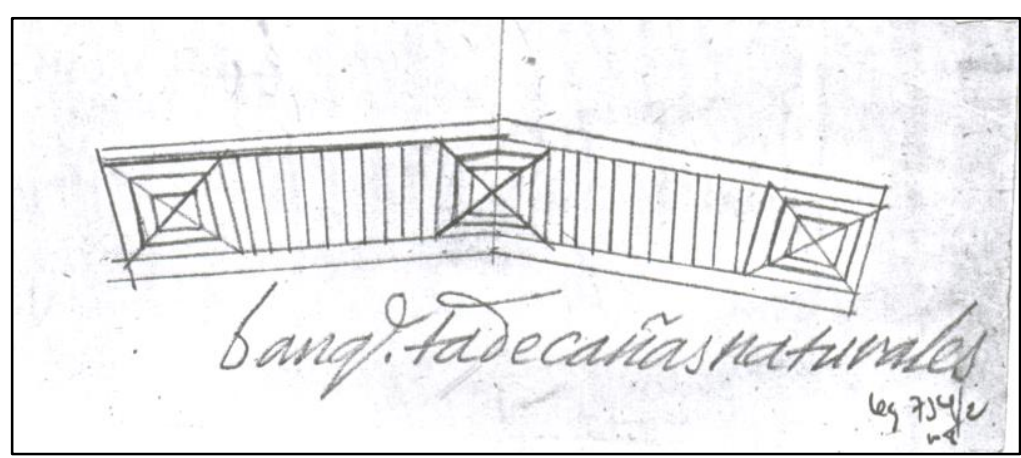

Fig. 10- Dibujo para un banco de cañas naturales. 1860, AHNOB. FN Leg. 734/2 nº 8.

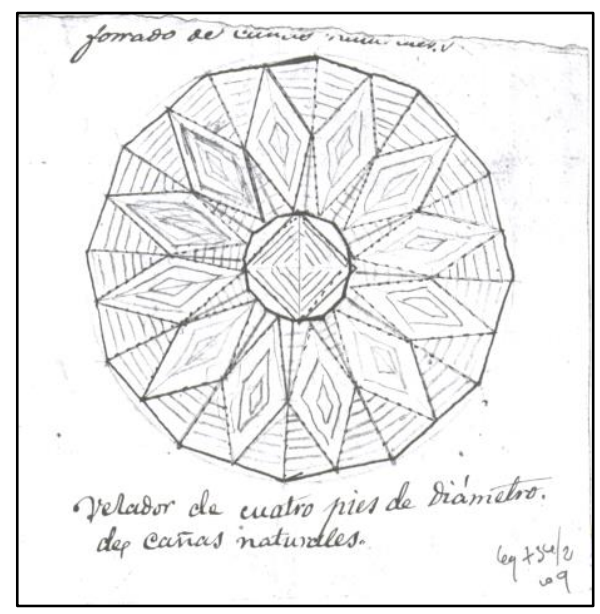

Fig. 11- Dibujo de velador de cuatro pies de diámetro de cañas naturales. 1860, AHNOB. FN Leg. $734 / 2 n^{\circ} 9$. 
Volviendo a la obra principal en el Jarama, y siguiendo un orden cronológico de los hechos, el 18 de julio se le reclamaron al apoderado Carlos García Llaguno otro ejemplar del plano de la obra que se intentaba practicar, y dos de la memoria facultativa, que no habían sido remitidos en el expediente de solicitud de licencia de obra al Gobierno Civil, y era un requisito legal. ${ }^{50}$

Al mismo tiempo, ese mismo 18 de julio, el Gobierno Civil de la Provincia mandó al solicitante que se fijasen en los sitios públicos de costumbre de ese pueblo los oportunos anuncios, para que todos los que pensasen tener derecho a oponerse a lo solicitado por el señor duque de Fernán Núñez presentasen sus reclamaciones en el preciso término de veinte días en ese Gobierno de Provincia. Transcurrido el plazo de veinte días, se remitirían al citado Gobierno los anuncios originales con las reclamaciones que se hubiesen presentado, o certificación de no haber ninguna en su caso. $^{51}$

Puestos los anuncios, y para adelantar tiempo de modo que no se pasasen los meses adecuados para trabajar en el río, porque de llegar las riadas habría que esperar al verano siguiente para hacerlas, Eugenio Barrón le pidió a Carlos Llaguno el día 26 de julio, el dibujo acotado que presentó al inicio, para estudiar la estacada y hacer un croquis sujeto a escala, junto a la pertinente memoria. También le solicitó algunas noticias de la época, como el tiempo en que se destruyeron las anteriores estacadas o señalar los límites del río donde estaban ubicadas las defensas. ${ }^{52}$

El día 28 de julio, Llaguno quedó en enviar el dibujo a Barrón y recabar la información solicitada. ${ }^{53}$ El 31 de julio le comunicó al ingeniero que una estacada que se estuvo haciendo en el mes de febrero de 1856, fue dañada por una avenida del mes de marzo, pero que una vez repuestas las estacas rotas a mediados de abril, soportó hasta los primeros días de febrero de 1858, en que de nuevo sufrió los embates de las aguas, quedando seriamente deteriorada; ninguna otra intervención se había hecho hasta la fecha actual.

En cuanto a los límites del río Jarama, hasta fines de 1855 eran, por la margen izquierda, el Prado de Paracuellos, y por la derecha, la parte del Malecon, que desde aquella época estaba convertido en una isla "formada por el cauce antiguo del río y el barro o rotura que hizo la desembocadura del arroyo Torrejon". ${ }^{54}$

El 7 de agosto se le reclamó a Barrón el croquis firmado por él y la memoria del proyecto, ya que había que reproducir la solicitud de permiso para hacer la estacada, y era urgente presentar toda la documentación. ${ }^{55}$

Las gestiones se dilataron, ya que el 3 de septiembre se avisó por carta a Eugenio Barrón para que indicase la hora, el sitio y el modo en que deseaba desplazarse a Barajas para examinar sobre el terreno el lugar donde reparar la estacada y levantar

50 AHNOB. FN Leg. 734/2 n 26.

51 AHNOB. FN Leg. 734/2 n 30.

52 AHNOB. FN Leg. 734/2 no 17.

${ }^{53}$ AHNOB. FN Leg. 734/2 no 16, 28 de julio 1860.

${ }^{54}$ AHNOB. FN Leg. 734/2 no 19, 31 de julio 1860.

55 AHNOB. FN Leg. 734/2 n ${ }^{\circ} 18,7$ de agosto 1860. 
dique. ${ }^{56}$ Se le reclamaron de nuevo los documentos, planos y memorias el 20 de septiembre, para presentarlos en el Gobierno Político de la Provincia. ${ }^{57}$

Finalmente presentó Eugenio Barrón un croquis y un informe que aunque está sin fechar, debió realizarse entre finales de septiembre y finales de octubre, que es cuando presentó sus dibujos y explicación del proyecto José Ramón de Eguía. La memoria de Barrón correspondería a un momento posterior a la visita que hizo a Barajas.

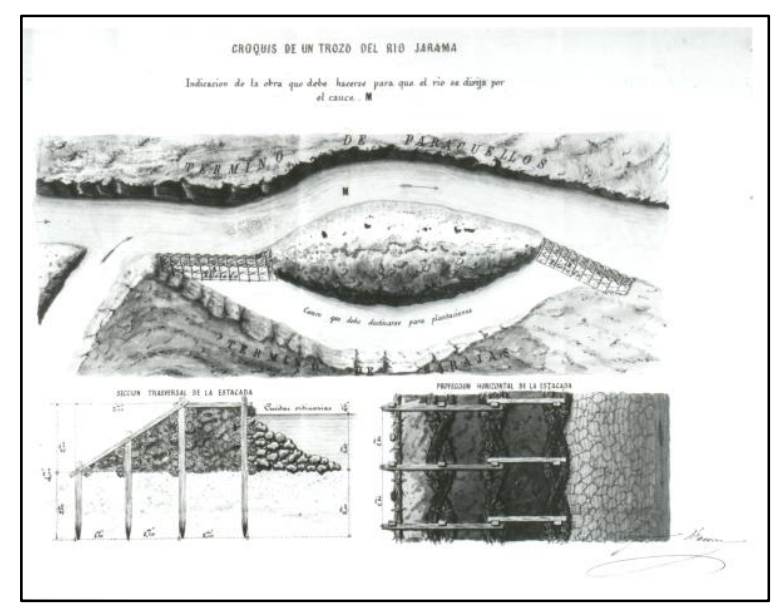

Fig. 12- Eugenio Barrón. Croquis de un trozo del río Jarama. Indicación de la obra que debe hacerse para que el río se dirija por el cauce M. 1860, AHNOB. FN Leg. 734/2.

Reproducimos el texto completo para poder entender lo que ha propuesto Barrón en el croquis:

La idea que conservo del trozo del Rio Jarama que vi en un corto espacio de tiempo, sin haber podido verificar ninguna medicion, es la que me ha servido para formar el adjunto croquis de la parte de terreno que trata de defenderse en el termino de Barajas y posesion del Exmo. Sr. Duque de Fernan-Nuñez = Lo que presento no es un plano de aquella localidad es solo una indicacion de la obra que debe ejecutarse con las acotaciones convenientes para su completa inteligencia. Al separarse el Rio en dos brazos y seguir la direccion $\mathbf{M}$ que es por donde lleva menos caudal, ha dejado una Ysleta ó parte alta que dificulta el paso del agua, y con mayor facilidad se dirige hacia la margen de Barajas socavando las orillas que son de tierra floja y robando en cada avenida una parte considerable de la posesión. Es conveniente y de un exito seguro emprender este verano el desmonte ó sea dragado de la Ysleta la arena que entorpece el paso del agua por el cauce $\mathbf{M}$ cuya porcion queda reducida por de pronto a abrir una zanja de pequeñas dimensiones, capaz de recibir la corta cantidad de agua que

\footnotetext{
56 Archivo Histórico de la Nobleza, Fondo Fernán Núñez (AHNOB FN) Leg. 734/2 nº 5, 3 de septiembre 1860 .

${ }^{57}$ AHNOB. FN Leg. 734/2 no 20. Se dice que celebran el completo restablecimiento de Eugenio Barrón, por lo que el retraso en la entrega de planos y documentos se podría deber a una enfermedad o percance sufrido por el ingeniero.
} 
ahora conduce el Rio y regularizar de este modo la corriente dejando bajo una rasante el talweg del Jarama. Practicada esta operacion el agua correrá por el cauce $\mathbf{M}$ y haciendo el cerramiento A la mayor altura que tomará el nivel del Rio, corroerá el terreno recientemente removido y se abrirá paso por la orilla de Paracuellos. Para que las aguas por retroceso no entren en el cauce de donde se las deje retirar, habrá que establecer una ligera estacada en $\mathbf{B}$ de mismas proporciones que la que se egecute en $\mathbf{A}=$ El cauce comprendido entre las dos estacadas debe llenarse de plantaciones y establecer salgueras, taray y otros vegetales de pronto y facil arraigo en el agua y estos obstaculos presentados en aquel pasage servirán para poco ó poco rellenando el terreno, depositando y conservandose en el los Depositos que arrastran las aguas en sus avenidas. La estacada que se proyecta y que juzgo es lo mas economico y apropiado para el obgeto que trata de ligarse, se compondrá de dos filas paralelas de pilotes o estacas de 4 á 5 metros de longitud para que queden despues de clavadas a martinete su parte superior 0,35 metros sobre el nivel de las crecidas ordinarias del Rio. Otras dos filas paralelas á las anteriores y de la misma altura formarán el talud de la estacada para fortificar convenientemente el macizo $=$ Los pilotes se colocarán en el sentido de la longitud de la estacada á la distancia de 1,80 metros y á la de 2 metros en el trasversal. Se ligarán unos y otros por medio de salchichones formados con las ramas de los arbustos que hay en aquella localidad, y las cuadriculas que resultan de este tejido se rellenarán cuidadosamente para construir un macizo consistente. En la parte de las aguas se apoyará un prisma triangular de piedra y arena, que luego el mismo curso de ellas irá obstruyendo. La estacada que se establece en $\mathbf{B}$ analoga á la anterior puede ser de menores proporciones. Con esta ligera idea y lo que manifiesta el dibujo acerca de construccion de la estacada, cuyos pormenores van acotados, una persona acostumbrada a hacer obras de esta especie en el Rio, tiene lo suficiente para llevar á cabo la que en mi sentir y no descuidando las plantaciones, han de producir la conservacion del terreno perteneciente a la posesion del Exmo. Sr. Duque de Fernan Nuñez. ${ }^{58}$

Por su parte, José Ramón de Eguía, como Director de Caminos Vecinales, va a firmar los otros dos dibujos que presentamos, y que a tenor de la memoria que les corresponde, estarían fechados el 30 de octubre de 1860.

\footnotetext{
${ }^{58}$ AHNOB. FN Leg. 734/2 no 22.
} 


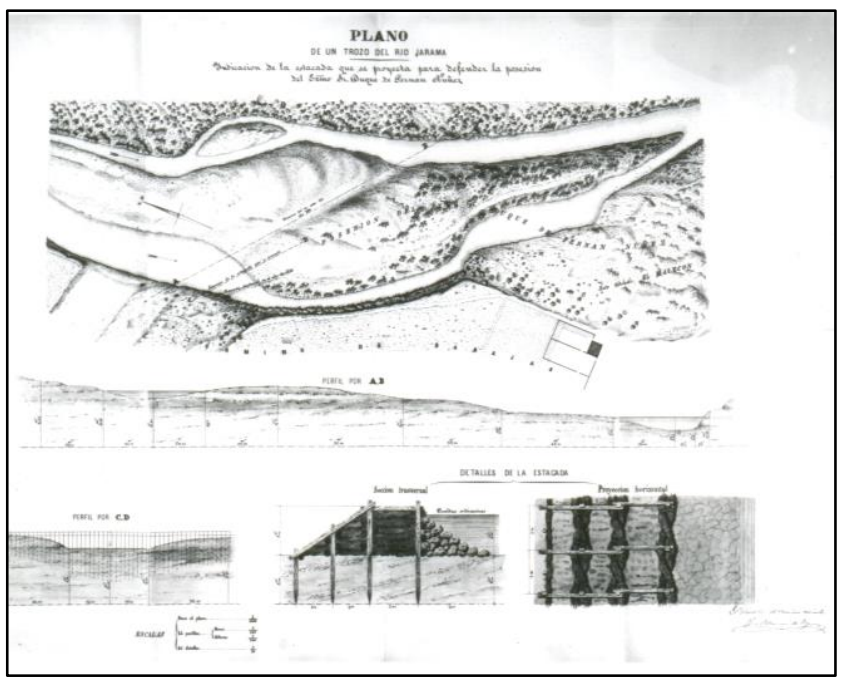

Fig. 13- José Ramón de Eguía. Director de Caminos Vecinales. Plano de un trozo del río Jarama. Indicación de la estacada que se proyecta para defender la posesión del Exmo. Sr. Duque de Fernán Núñez: 1860, AHNOB. FN Leg. 734/2.

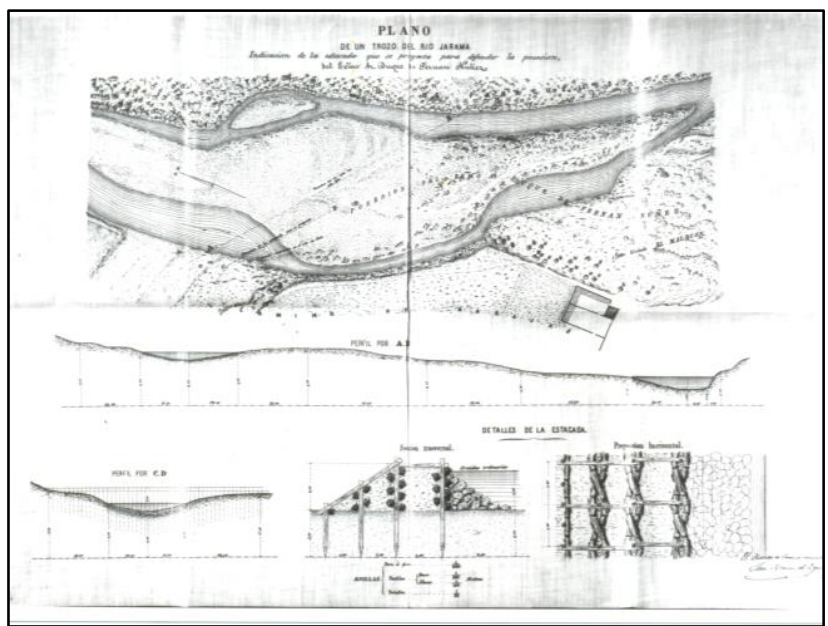

Fig. 14- José Ramón de Eguía. Director de Caminos Vecinales. Plano de un trozo del río Jarama. Indicación de la estacada que se proyecta para defender la posesión del Exmo. Sr. Duque de Fernán Núñez. 1860, AHNOB. FN Leg. 734/2.

$\mathrm{Al}$ igual que en el caso anterior, reproducimos la explicación que acompañaba a los planos, que es la siguiente:

Obra que se proyecta en el Rio Jarama para defender la posesion del Exmo. Sor. Duque de Fernan Nuñez en el termino de Barajas. El curso del Rio Jarama, durante muchos años ha seguido la direccion que indica el plano en el ramal que corre por el 
lado de Paracuellos, pero á consecuencia de varias avenidas fue depositando en el centro de su lecho bastante cantidad de piedra y arena y las aguas, encontrando de poca consistencia la marjen derecha del Rio, socavaron el terreno y se formó la bifurcación y por consiguiente la isleta, robando esta nueva direccion del Jarama una parte considerable de la posesion del Sor. Duque situada en el termino de Barajas. Como cada avenida que se ha ido sucediendo ha aumentado segun es natural los daños que produce la socavacion del terreno, en el año 1856, el propietario mandó construir una estacada que defendiese su posesion, la cual fué destruida en gran parte con las avenidas del mes siguiente de Marzo. Repuestas varias estacas en el siguiente mes de Abril se logró contener los desastrosos efectos de la corriente, pero la riada estraordinaria de Febrero de 1858, arrebató la obra construida, las aguas acometieron todavia mas la marjen derecha y desde entonces nada se ha practicado en el cauce del Rio. En este estado la obra que hoy se proyecta para contener el Rio y defender la posesion a fin de que el curso de las aguas siga su primitiva direccion, queda reducida á abrir un cauce de comunicacion entre los dos brazos del Rio atravesando la isleta que es propiedad del Duque (como que es una parte del terreno suyo) siguiendo el curso que manifiesta la linea A. B. que es por donde primero cruza el agua cuando hay alguna avenida.

Este lijero desmonte y el dragado de la arena que entorpece ó dificulta el paso de las aguas a la entrada del antiguo cauce, serviran para regularizar la corriente y dejar bajo las rasantes que convengan el talweg del rio Jarama. Practicada esta operacion las aguas correrán en gran parte por el nuevo cauce abierto en la isleta y, por el antiguo, y corroerán el terreno recientemente removido abriendo y ensanchando mas su paso. La estacada que se proyecta contendrá el agua á mayor altura y contribuirá notablemente á lograr los efectos que hemos manifestado. Detras de la estacada se debe hacer una fuerte plantacion en el terreno bajo que queda en seco, correspondiente a la posesion del Duque, poniendo chopos, salgueras, taray, y otros vejetales de pronto y facil arraigo en el agua, y estos obstaculos presentados en aquel sitio serviran para las defensas de las marjenes flojas del Rio en el termino de Barajas. Establecemos las estacadas en el punto que indica el plano por debajo del arroyo Baldebebas, que aun cuando está en seco gran parte del año, tiene no obstante sus avenidas en el invierno. La estacada que se proyecta y parece mas apropiada al objeto que trata de lograrse se compondrá de dos filas paralelas de pilotes o estacas de cuatro a cinco metros de altura para que queden despues de clavados a martinete su parte superior o cabeza a 0,35 metros sobre el nivel de las crecidas ordinarias. Otras dos filas paralelas á las anteriores y de menor altura formaran el talud de la estacada y fortificarán convenientemente el macizo. Los pilotes se colocarán en sentido lonjitudinal de la estacada a la distancia de 1,80 metros y a la de dos metros en el trasversal. Se ligarán unos á otros por medio de salchichones formados con las ramas de los arbustos que hay en abundancia en aquella localidad y las cuadriculas que resultan de este tejido se rellenarán cuidadosamente para constituir un macizo resistente. En la parte de las aguas se apoyará un prisma triangular de piedra y arena que luego el mismo curso de las aguas irá obstruyendo y evitará las filtraciones a traves de la obra que se proyecta. El plano que se acompaña contiene los detalles suficientes para la ejecucion de la estacada, cuyos pormenores van acotados.

El perfil lonjitudinal de la linea A B. demuestra el desmonte que habria de ejecutar en la posesion del Sor. Duque para unir los dos brazos del rio. El corte C. D. indica la seccion del Rio en el sitio que conviene establecer la estacada. Por último el plano 
general ha sido levantado tomando una linea como base, y haciendo estacion en varios puntos de ella, se han dirijido visuales a los mas notables para sacar unas veces por medicion de los lados, y otras por intersecciones el curso del Rio Jarama y la configuracion jeneral del terreno. Madrid 30 de Octubre de 1860. El Director de Caminos vecinales, José Ramón de Eguía. ${ }^{59}$

A pesar de toda la tramitación que hemos expuesto en sus diferentes etapas, y de los diseños presentados con sus correspondientes memorias, pensamos que, habiendo llegado al mes de noviembre de 1861, se aplazaron las obras hasta que llegase de nuevo el momento más propicio para retomar el proyecto. Sin embargo, el 15 de junio de 1861, Eugenio Barrón le escribió al duque de Fernán Núñez una carta en la que le decía "que el corto estudio que hizo y al que puso su nombre en el plano, solo fue una idea que por ahora no puede tener aplicación"; le rogaba que no insistiese en querer dar valor a lo que no lo tiene, y que le pesaba no atender a su petición. ${ }^{60}$

La documentación consultada indica que el 10 de marzo de 1863, se ofreció el reactivar el expediente para conseguir la autorización y licencia para reconstruir un dique en el Jarama en el Soto del Malecón, en el término de Barajas. Se recordaba que aún se tenían que remitir al Gobierno de Provincia el plano de la obra y dos ejemplares de la memoria tal y como se solicitaron por carta el 18 de julio de $1860 .^{61}$

Dos días después, el duque de Sesto escribió al Gobernador de la Provincia y le indicó que le remitiese la memoria facultativa que se presentó en un principio para solicitar licencia y diese por terminado el expediente, ya que el duque de Fernán Núñez había desistido de la ejecución de esas obras "por no ser de necesidad en la actualidad". ${ }^{62}$ El 27 de marzo de 1863 se procedía a devolver la mencionada memoria facultativa al apoderado general del solicitante, Carlos García Llaguno. ${ }^{63}$

A partir de esa fecha no hay más documentos que nos aclaren si se volvió a retomar el proyecto, o simplemente se abandonó y siguieron produciendo daños las riadas en esa zona del Jarama. Sí tenemos noticia de una reclamación que hizo el 11 de junio de 1864 don Antonio Sánchez de Milla, vecino de Madrid, de un terreno de la parte baja del Malecón que lindaba con tierras de los condes de Barajas, y que él consideraba de su propiedad. La petición se desestimó porque el reclamante consideraba para marcar las lindes lo que él creía cauce del Jarama, y no era otra cosa que un brazo accidental de éste, producto de las riadas que ocurren en años lluviosos (se añadía este dibujo explicativo). ${ }^{64}$

\footnotetext{
${ }^{59}$ AHNOB. FN Leg. $734 / 2 \mathrm{n}^{\circ} 3$.

${ }^{60}$ AHNOB. FN Leg. 734/2 n 15.

${ }^{61}$ AHNOB. FN Leg. 734/2 no 24.

${ }^{62}$ AHNOB. FN Leg. 734/2 n 23.

${ }^{63}$ AHNOB. FN Leg. 734/2 no 25, 27 de marzo 1863.

${ }^{64}$ AHNOB. FN Leg. 734/2 no 25, 11 de junio 1864.
} 


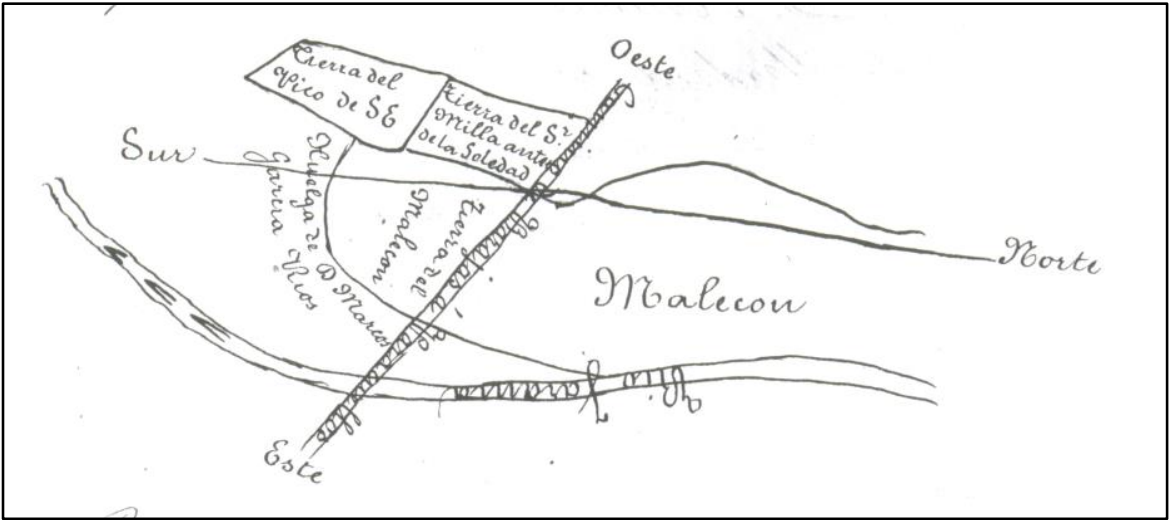

Fig. 15- Vicente de Hombre. Dibujo de la zona del Malecón y otras fincas limitrofes. 1864, AHNOB. FN Leg. 734/19.

Para finalizar queremos mencionar un artículo que el ingeniero Eugenio Barrón Avignón publicó en la Revista de Obras Públicas en 1861, justo después de haber realizado el croquis y estudio para reparar el estacado y dique en el río Jarama, porque recoge en él la problemática de las consecuencias de las crecidas de las aguas, y las medidas que se pueden tomar. ${ }^{65}$

A modo de resumen, reflexiona sobre el terrible problema que a nivel nacional han supuesto las inundaciones que han provocado las continuas lluvias que habían estado precipitando agua cincuenta días seguidos desde noviembre a finales de diciembre de 1860. Las crecidas extraordinarias de los ríos, como las de los años de 1846, 1855, 1856 y 1860, dañaban cultivos, destruían construcciones, mataban ganado y costaban vidas.

Critica las escasas medidas puntuales que tomaba el Gobierno y la desaparición de los bosques y despoblación vegetal de los montes, ya que apostaba por el aprovechamiento de los recursos que proporciona la propia naturaleza para paliar desastres.

Dentro de su campo de conocimiento, y en cuanto a construcciones hidráulicas, apuesta decididamente por la construcción de diques transversales frente a los longitudinales, porque evitan desastres y proporcionan depósitos de agua muy útiles para la agricultura; se harían también presas para derivaciones de riego, y el Gobierno debería prestar ayudas y subvenciones para sufragar los gastos de ejecución de estas obras, que benefician a todo el país.

A tenor de lo que refleja en su escrito, tal vez el plan de Eugenio Barrón para la obra en el Jarama fuese más ambicioso y costoso que el presentado en principio al duque de Fernán Núñez, y se pareciese más al que plantea en su artículo, pero lamentablemente no se pudo llevar a cabo.

${ }^{65}$ Eugenio Barrón y Avignón. "Inundaciones", en Revista de Obras Públicas (Madrid: 1861, 9, tomo I (5), 57-60. 


\section{REFERENCIAS BIBLIOGRÁFICAS}

AA.VV., Barajas. Cuatro mil años de historia a través de la arqueología. Propuesta para la puesta en valor del patrimonio arqueológico del distrito de Barajas. (Barajas, distrito BIC (recurso digital), 2018). http://barajasbic.blogspot.com/2018/09/barajascuatro-mil-anos-de-historia.html (consultado el 10 de febrero de 2019).

Eugenio Barrón Avignón. "Madrid: Prolongación de la calle de Bailen y puente de hierro para la de Segovia", en Revista de Obras Públicas (Madrid: 1861, 9, tomo I, $\mathrm{n}^{\circ}$ 18), 217-224; y con el mismo título, (Madrid: 1861, 9, tomo I, no19), 229233.

Eugenio Barrón y Avignón. "Inundaciones", en Revista de Obras Públicas (Madrid: 1861, 9, tomo I (5), 57-60.

Juan Antonio Becerril Bustamante. "Siglo y medio de innovaciones en la construcción: la ingeniería civil española a través de la Revista de Obras Públicas", en Informes de la Construcción (Madrid: Vol. 60, 510, págs. 7-34, abril-junio 2008). El artículo de Eugenio Barrón se publicó en la citada Revista de Obras Públicas en 1861, tomo I, n 23, págs. 283-286.

Teresa Bullón Mata, "Avenidas fluviales y precipitaciones en las cuencas de los ríos Jarama-Tajo al final del siglo XVI", en Boletín de la Asociación de Geógrafos Españoles (Madrid: nº 60, 2012), 77-90.

Teresa Bullón Mata, "Morfología fluvial del río Jarama entre los siglos XVI y XIX. Datos documentales y cartográficos", en Temas y lugares (recurso electrónico: homenaje a Eduardo Martínez de Pisón/coord. por María Eugenia Arozena Concepción, Carmen Romero Ruíz, 2016), 77-94.

Carmen Castells, Eguía Madariaga, José Ramón De (Auñamendi Entziklopedia [on line], 2019) http://aunamendi.eusko-ikaskuntza.eus/eu/eguia-madariaga-joseramon-de/ar-37235/ (consultado el 25 de enero de 2019).

Clementina Díaz y de Ovando, Invitación al baile. Arte, espectáculo y rito en la sociedad mexicana (1825-1910) (México, UNAM, 2006, vol. II), 589-592.

Francisco Fernández Izquierdo, Ángel Alloza Aparicio y Francisco Javier Moreno Díaz del Campo, La Presa del Vado y el Canal del Jarama. (Madrid: Proyecto de investigación. Fundación Canal. Canal de Isabel II, 2016). 
Inmaculada García Lozano y Mario Sánchez Cachero (fot.). "El Palacio de Fernán Núñez, una joya por conocer del patrimonio arquitectónico y cultural madrileño", en La gatera de la Villa, nº 22 (Madrid, año 2016), 37-52.

Inmaculada García Lozano. "El palacio y la colección de los Duques de Fernán Núñez en imágenes. 1839-1939", en Actas I Jornadas sobre Investigación en Historia de la Fotografía. 1839-1939: Un siglo de fotografía. (Hernández Latas, José Antonio (ed.) 2017), 185-196.

Alejandra Hernández Clemente, Ricardo Bellver y Ramón: su obra escultórica: un estudio bistoriográfico y documental (Madrid: Tesis, E-Prints Complutense, 2012).

Cristóbal Marín Tovar y Virginia Tovar Martín, El Palacio Parcent (Madrid: Ministerio de Justicia, 2009).

Cristina del Prado Higuera, El Todo Madrid: La corte, la nobleza y sus espacios de sociabilidad en el siglo XIX (Madrid: Fundación Universitaria Española, 2013), 112-113.

Luís Rubio Gil, Rosales. El testamento de Isabel la Católica (Edición digital: Ediciones del Serbal, 2011), 44.

Eulalia Ruíz Palomeque, Ordenación y transformaciones urbanas del casco antiguo madrileño durante los siglos XIX y XX (Madrid: Instituto de Estudios Madrileños, 1976).

Fernando Sáenz Ridruejo. "Datos para el estudio sociológico del cuerpo de ingenieros de caminos a mediados del siglo XIX", en Actas II Congreso de la Sociedad Española de Historia de las Ciencias. (Madrid: Vol. 2, 1984), 361-378.

Carlos Saguar Quer, Arquitectura funeraria madrileña del siglo XIX (Madrid: Universidad Complutense, 1989).

Vicente Sancho del Castillo. Baile de trajes en casa de los duques de Fernán Núnez: 25 de febrero de 1884/apuntes tomados por Vicente Sancho del Castillo y Emilio Bravo y Moltó (Madrid: Imprenta y esterotipia de El Liberal).

Mariano Serrano Pascual. "Romper con las tradiciones. Más allá del arco, puentes para la modernidad, en la Arquería del Ministerio", en Revista del Ministerio de Fomento (Madrid: $n^{\circ}$ 659, 2016), 44-47.

José Antonio Vigara Zafra. "Los Fastos de los III duques de Fernán Núñez: nuevas políticas de construcción de la imagen nobiliaria en el siglo XIX", en Caiana. Revista de Historia del Arte y Cultura Visual del Centro Argentino de Investigadores de Arte (Buenos Aires: CAIA. no 11, Segundo semestre, 2017), 69-83. 
José Antonio Vigara Zafra. "El cementerio Neoclásico del VI Conde de Fernán Núñez: Un ejemplo de distinción social y apropiación del espacio funerario", en Laboratorio de Arte (Sevilla: no 28 (2016), 433-454.

Recibido: 1 de marzo de 2019

Aprobado: 5 de abril de 2019 